\title{
Utilização do Focus Group para avaliação de percepção do consumidor em produtos orgânicos
}

\author{
Valéria França de Souza \\ Flávia De Floriani Pozza Rebello \\ Elisabete Maria da Graça Costa do Nascimento \\ Universidade Federal Rural do Rio de Janeiro - UFRRJ \\ vssouzafrana@yahoo.com.br; flavi.rebello@gmail.com.br; betecosta@pop.com.br
}

\section{RESUMO}

Focus Group é definida como um exercício de dinâmica de grupo, através de sessões de entrevistas com reduzido número de participantes, informação e opinião sobre algum produto que pode ser seguida por pesquisas subseqüentes. O objetivo do presente estudo foi avaliar a percepção do consumidor em relação à qualidade de produtos orgânicos com a finalidade de uso do Focus Group. O Focus Group foi conduzido em uma sessão, em uma sala apropriada com um grupo de mulheres, seguindo roteiro de entrevistas. Neste estudo foi observado que os participantes se mostraram interessados (em participar ou nos produtos orgânico) e a maioria declarou consumir poucos produtos orgânicos. Os resultados sugerem o investimento de futuras pesquisas visando incentivar o consumo de produtos orgânicos.

Palavras-chave: sessões de Focus Group, consumidor, pesquisa qualitativa, produtos orgânicos.

\section{Using Focus Groups to evaluate consumer perception of organic products}

\begin{abstract}
Focus Group is defined as an exercise of group dynamics, through sessions of interviews with reduced number of participants, information and opinion on some product that can be followed by subsequent research. The objective of the present study was to evaluate the perception of the consumer in relation to the quality of organic products with the purpose of use of the Focus Group. The Focus Group was performed in a session had been lead in an appropriate room with women group, following script of interviews. In this study it was observed of what they showed interested and the majority of the consumers had declared little organic products consumption. The results suggest the investment of future research aiming at to contribute for the growth of the organic culture.
\end{abstract}

Key-words: Focus Group sessions, consumers, qualitative research, organic products.

\section{INTRODUÇÃO}

Estudos têm comprovado o crescimento do mercado consumidor de alimentos orgânicos em diversos países. No Reino Unido, tal mercado cresce exponencialmente desde os anos 80 (Davies et al., 1995). Desde 1990, o crescimento tem girado torno de $20 \%$ ao ano, prevendo que o mercado cresça 20 vezes até 2005 (Produtos, 2001), dados da FAO indicam que em 1997 
a agricultura orgânica movimentou cerca de US\$ 8,7 bilhões.

Considerando o mercado interno, apesar da baixa renda per capita, um número crescente de consumidores expressa preocupação com temas relacionados à segurança alimentar, meio ambiente, bem estar social e saúde, mostrando-se dispostos a pagar mais caro por "alimentos naturais", que não contenham produtos químicos ou outras fontes de contaminação (Regmi et al., 2001; Unctad, 1999).

O objetivo deste trabalho foi avaliar a percepção do consumidor em relação à qualidade de produtos orgânicos tomado por base o sistema de avaliação Focus Group (Grupo focal).

O método permite um maior entendimento de como se formam as diferentes percepções e atitudes do grupo acerca de um fato, prática, produto ou serviço. A coleta de dados através de Grupo Focal tem como uma de suas maiores riquezas se basear na tendência humana de formar opiniões e atitudes na interação com outros indivíduos ( Krueger, 1988). A essência do grupo focal consiste justamente em se apoiar na interação entre seus participantes para se obter dados, a partir de tópicos que são fornecidos pelo moderador do grupo (Morgan, 1988). Os participantes são selecionados por apresentarem certas características em comum que estão associadas ao tópico que está sendo pesquisado através do Grupo Focal. Ele contrasta, nesse sentido, com dados colhidos em questionários fechados ou entrevistas individuais, onde o indivíduo é estimulado a emitir opiniões sobre assuntos que talvez ele nunca tenha pensado a respeito anteriormente. As pessoas em geral precisam ouvir as opiniões dos outros antes de formar as suas próprias, e constantemente mudam de posição. Em alguns casos, fundamentam melhor sua posição inicial quando expostas a discussões de grupo (Krueger; Morgan, 1988).
É exatamente este processo que o Grupo Focal tenta captar. Assim, definidas as características das pessoas ou o grupo social a ser estudado, seu recrutamento deve visar abarcar sua variabilidade (etária, de gênero, de classe social se for o caso) e ter em vista as observações feitas em tópico anterior e evitar alocarem em um só grupo pessoas do mesmo círculo imediato de convivência ou que apresentem características muito contrastantes. Observadas estas regras básicas, o recrutamento de voluntários pode se dar: de modo aleatório pelo telefone, utilizando-se um breve questionário de "screening" para selecionar os participantes adequados; por anúncios de jornal; através do atendimento em serviços de saúde pertencentes a população alvo do estudo (Trost, 1986), ou através de informantes chave da comunidade em questão (Gregor, \& Galaska, 1990). A possibilidade de fornecer algum incentivo aos seus participantes (almoço em um restaurante, participação em sorteio, pagamento em dinheiro) pode ser um fator de peso na possibilidade de sucesso do recrutamento. Cabe ao moderador do grupo criar um ambiente propiciador para que diferentes percepções e pontos de vista venham à tona, sem que haja nenhuma pressão para que seus participantes votem, cheguem a um consenso ou estabeleçam algum plano.

É uma técnica utilizada na pesquisa de mercado qualitativa, na qual se emprega a discussão moderada entre 8 e 12 participantes. Discussões de grupo costumam durar entre uma hora e meia e duas horas. Os Focus Group são usados nos temas mais diversos. Muito freqüentemente são usados em testes de publicidade, testes de conceito e como pré-fase de estudos quantitativos maiores.

Os clientes podem observar a discussão por detrás de uma janela espelhada de um lado. Os participantes não podem ver do lado de fora, mas os clientes podem ver a discussão. Normalmente, uma câmera de vídeo é usada para gravar a discussão para ser vista 
por outros que não puderam estar presentes no momento. Os pesquisadores examinam mais do que apenas as palavras. Eles estão interessados nas expressões faciais, linguagem corporal e dinâmica de grupo. Por vezes, são criadas transcrições de gravação nos pontos mais importantes.

Por ser uma técnica subjetiva, o Focus Group é considerado pesquisa preliminar que pode ser seguida por pesquisas quantitativas (Calder, 1977).

Para que os objetivos sejam alcançados, é necessário que o moderador observe atentamente alguns itens:

a) Seus participantes não devem idealmente pertencer ao mesmo círculo de amizade ou trabalho. O objetivo é evitar que a livre expressão de idéias no grupo seja prejudicada pelo temor do impacto (real ou originário) que essas opiniões podem ter posteriormente Morgan (1988). O grupo focal deve procurar mimetizar, segundo Kruguer (1988), as longas conversas que freqüentemente duas pessoas desconhecidas se engajam durante uma viagem de avião. A franqueza e a profundidade de troca de experiências ocorridas num contexto como esse muitas vezes são especialmente ricas justamente pelo fato dos seus participantes não terem nenhum compromisso posterior de se verem ou conviverem a partir desse encontro casual. Embora essa característica do grupo focal seja altamente desejável, ela nem sempre é possível, como é o caso, por exemplo, da utilização de grupos focais para coleta de dados em pequenas comunidades (World Health Organization, 1992).

b) Seus participantes devem ser homogêneos em termos de características que interfiram radicalmente na percepção do assunto em foco, visando garantir um clima confortável para a troca de experiências e impressões de caráter muitas vezes pessoal. Em pesquisas sobre abuso de substâncias, por exemplo, é freqüente a constituição de diferentes subgrupos para as diversas faixas etárias, gênero, orientação sexual, renda e etnia. É importante enfatizar, no entanto, que a busca de homogeneidade em algumas características pessoais não deve implicar na busca de homogeneidade na percepção do problema. Se assim fosse, o grupo focal perderia sua riqueza fundamental, que é o contraste de diferentes perspectivas entre pessoas semelhantes. Enfim, para Morgan (1988), os participantes devem ser selecionados de modo que o grupo não resulte em incontornáveis discussões frontais ou em recusa sistemática de emitir opiniões.

\section{MATERIAL E MÉTODOS}

\section{Participantes das sessões}

Foi realizado um Focus Group a fim de realizar uma discussão planejada com o objetivo de se identificar a percepções do grupo em relação aos produtos orgânicos.

O roteiro das entrevistas foi elaborado com questões gerais e específicas (Quadro 1). 
Quadro 1. Questionário da entrevista de Focus Group

\section{Questões Gerais:}

1. O que é uma boa alimentação para você?

2. Na sua opinião, quais os alimentos que compõem uma boa alimentação?

3. Se responderem frutas, legumes e verduras, em relação às frutas, legumes e verduras, quais os mais consumidos por você?

4. Onde costuma comprar e com que freqüência compra frutas, legumes e verduras?

5. Que critérios (ou aspectos) você leva em consideração na hora da compra de frutas, legumes e verduras?

6. O que entende por qualidade de frutas, legumes e verduras?

7. Na sua opinião do que depende a qualidade das frutas, legumes e verduras ? Ou o que seria necessário para a garantia das frutas, legumes e verduras?

Questões Específicas

8. Já ouviu falar em alimento orgânico?

9. O que você entende por alimento orgânico?

10. O que levaria você a consumir frutas, legumes e verduras orgânicas?

A condução dos testes foi realizada em uma sessão com 8 alunas de Pós-Graduação da Universidade Federal Rural do Rio de Janeiro da disciplina "Como conhecer e interpretar os desejos do consumidor", com aproximadamente $1 \frac{1}{2}$ hora de duração sob a orientação de uma moderadora treinada (professora).

A faixa etária dos participantes dos testes foi entre 25 e 50 anos.

As informações coletadas das participantes são confidenciais e seus nomes não aparecem em muitas análises ou pesquisas publicadas.

A sessão foi gravada e realizada em uma sala apropriada, livre de distrações externas, acompanhadas de uma moderadora, com a finalidade de garante na transcrição a fidelidade nas palavras das informações dos próprias do consumidor.

\section{Condução das sessões do Focus Group}

Ao iniciar a sessão, a moderadora cumprimenta a todos e explica brevemente como será a condução dos trabalhos.
A sessão de Focus Group foi realizada seguindo um roteiro previamente elaborado pela moderadora para a condução da sessão.

A moderadora inicia os trabalhos com as questões gerais, a fim de que o grupo possa expressar suas opiniões para que haja interação do grupo. Em seguida, aborda as questões específicas, objeto de estudo do presente trabalho.

A moderadora, responsável pela sessão, leva em consideração algumas características como: compreensão natural do problema da pesquisa; ser familiar com recentes informações do tópico ou objeto de discussão; decidir a estratégia e a sequência das questões com facilidade e discussão; e conhecimento das análises e interpretação dos resultados (Stewart \& Shandasani, 1990).

\section{Tratamento dos Dados}

Durante a sessão, as alunas da pesquisa registraram as opiniões e impressões dos participantes (Quadro 2). 


\section{Quadro 2. Transcrição da sessão de "focus group" realizada em sala apropriada}

Supondo um grupo de pessoas não consumidoras de alimentos orgânicos e potenciais compradoras de hortaliças orgânicas.

Em sua opinião o que é uma alimentação saudável?

- É uma alimentação onde a pessoa se sente bem, que pode trazer benefício nutricional;

- É uma alimentação destituída de muita gordura animal, quando redunda em saúde para a pessoa; quando alcança um bem-estar, sem ficar sempre doente;

- Alimentação saudável tem que ser equilibrada; sem gordura animal em excesso.

Porém o uso de coisas bem variadas sem se exceder em nada;

- Tem que ter equilíbrio, devendo-se usar carnes magras, acrescentando de alimentos qu estejam o mais próximo do natural;

- A alimentação saudável é muito chata, muito sem sabor;

- Alimentação saudável é quando se come e não se passa mal, quando se tem um grau de qualidade.

Quais são os alimentos que compõem uma boa alimentação?

- Frutas, verduras e legumes;

- Peixe;

- Nozes, castanhas e frutos oleaginosos que são consumidos geralmente no Natal, são alimentos essenciais para uma boa alimentação. Quais são as frutas e legumes que vocês consomem mais?

- Alface, couve, cenoura, batata, tomate, berinjela, nabo, frutas variadas;

- Mamão, uva, melancia, maçã, banana, melão, abacaxi.

Onde e com que freqüência costuma comprar frutas, legumes e verduras?

- Eu geralmente compro as frutas no sacolão;

- Mercado.

Que critério você leva em consideração na compra de frutas, legumes e verduras?

- Maturação, não muito verde;

- Não muito madura;

- Tamanho das frutas e legumes;

- O tamanho influi muito.

Do que depende a qualidade das frutas, legumes e verduras? Ou o que seria necessário para garantir a qualidade das frutas, legumes e verduras?

- Quando não é modificado geneticamente;

- Não tem agrotóxico;

- Se o lugar onde é vendido tem segurança com relação aos roedores e insetos;

- Preço;

- Se estão amassados, feridos, com partes apodrecidas;

- Comercialização;

- Rachaduras que possibilitam a contaminação.

E em casa? Como a qualidade pode ser mantida?

- Lavar e higienizar os produtos antes de armazená-los em casa;

- Preservar em locais próprios na geladeira, como na gaveta de baixo;

- Lavar as mãos na hora de consumir;

- Na hora do preparo estar devidamente higienizado;

- Abrir e consumir tudo para evitar sobras. O corte na fruta a expõe demais;

- Comprar só o que vai consumir, pois não precisa ir para a geladeira e fica mais natural;

- Frutas geladas e naturais.

Vocês já ouviram falar em alimento orgânico? O que vocês entendem por alimento orgânico?

- Alimento orgânico é aquele produzido de uma forma natural, sem aditivos, agrotóxicos, sem adicionar produtos que possam passar para o alimento durante o plantio;

- Sem utilização de muita tecnologia;

- Orgânico é onde não coloca agrotóxico naquele cultivo;

- Produto orgânico é aquele certificado;

- A garantia de orgânico é a ausência de pesticidas;
- Muitos produtos orgânicos podem trazer problemas ao consumir por trazerem uma carga microbiana alta com o esterco utilizado na adubação;

- Produtos orgânicos podem trazer benefícios, já que já existem grandes propriedades trabalham com agricultura orgânica, mas eu acho que agricultura orgânica de uma forma geral ainda é um nicho de mercado;

- Poucas pessoas entendem de agricultura orgânica. O tempo levado para produzir um alimento orgânico é muito longo. Com isso a demanda do mercado não é atendida;

- Alimento sem modificações genéticas, sem agrotóxicos, que preservem o meio ambiente;

- Alimento orgânico é aquele que é plantado na casa da pessoa.

Pra vocês qual é demanda do consumidor com relação à qualidade de alimento orgânico disponível?

- Eu não conheço ninguém que procura;

- Apenas pessoas que tem um pouco de conhecimento é que procuram;

Continuação do quadro 2

- As pessoas que têm maior acesso à cultura são as que procuram;

- As pessoas que tem maior conhecimento em alimento são as que mais buscam tais produtos;

- As pessoas até podem e sabem que o orgânico é mais saudável, mas quando vêem que é sujo, pequeno e mais caro preferem não comprar;

- A partir do momento em que se consiga uma produção maior, que se diminuam os preços, as pessoas vão naturalmente ter um poder de escolha maior;

- Por mais que a população de baixa renda saiba dos benefícios da utilização desses produtos, não tem condições de comprar;

- Os de maior renda não estão muito habituados a consumir produtos orgânicos por não encontrarem com facilidade e não terem muita formação sobre a importância deles.

O que vocês acham que poderia ser feito em termos de produção e conservação para melhoria da qualidade dos produtos orgânicos?

- Manter adequada a temperatura do local onde eles serão expostas;

- Mais estudos;

- Melhorar o tamanho dos alimentos, já que estes são tão menores que os que utilizam agrotóxicos;

- Pesquisar os nutrientes necessários para determinada planta e fornecê-los a ela;

- Saber trabalhar com o esterco, que é o adubo natural, de maneira correta;

- Desenvolver estudos e técnicas agrícolas que vão melhorar o mercado orgânico.

Como vocês vêem a relação da informação com o consumidor?

- É um problema porque os consumidores não têm a informação de que o alimento orgânico é mais benéfico que os demais.

Quem vocês acham que deveria dar informações sobre orgânicos?

- Pessoas da área de alimentos;

- Profissionais de saúde;

- Equipes do governo dentro de supermercados, de hospitais;

- A televisão, que convence os consumidores;

- Mídia em geral (televisão, rádio, jornais, revistas);

- Palestras educativas nas escolas com crianças e adolescentes para eles criarem hábitos melhores e influenciarem a família;

- Programas, como de Ana Maria Braga, Globo Rural, Globo Repórter e Fantástico.

O que levaria você a consumir mais frutas, legumes e verduras orgânicos? Qual seria a motivação de vocês?

- Disponibilidade e preço;

- Facilidade, maior acesso, maior venda. Não é muito encontrado;

- Menor preço.

Vocês estão dispostos a consumir produtos orgânicos?

- Se tiverem o mesmo preço dos não orgânicos, sim. 
Foi utilizado na análise e interpretação dos dados quatro páginas transcritas na sessão de Focus Group.

De acordo com Stewart \& Shandasani (1990), para cada pesquisa exploratória, a utilização do Focus Group utilizada é uma simples narrativa descritiva apropriada através da análise dos resultados.

Os dados obtidos foram registrados nos Quadros 1 e 2.

\section{RESULTADOS E DISCUSSÃO}

O resultado da sessão do Focus Group estão apresentados nos Quadros 3 e 4.

Dentro do grupo participante consideraram que uma alimentação saudável, é onde uma alimentação onde a pessoa deve se sentir bem e com qualidade microbiológica. Observa-se nessa frase que a qualidade microbiológica implica em um fator determinante na aquisição de um alimento.

Nos resultados os participantes mostraram que dentre dos alimentos que compõem uma boa alimentação destacam-se as frutas isto implica então a tendência de se alimentar de produtos frescos.

Foi considerado que o vegetal que é o mais consumido é o alface. Poderia se considerar que sendo um produto orgânico a probabilidade de ser o mais consumido entre eles.

A freqüência do consumo na compra dos vegetais é considerada alta a disponibilidade no mercado e baixa disponibilidade no hortifruti. Esta consideração mostra que a maioria das pessoas compram em supermercados que certamente está relacionada com os preços pois ficou caracterizado que nos hortifruti poderia estar relacionada aos preços altos nos estabelecimentosd de hortifruti.
Foi observado pelo grupo participante que os critérios que devem ser levados em consideração na compra de vegetais seria a maturação e o preço como fator limitante para o consumo.

Muito dos participantes consideram como negativo o alimento geneticamente modificado. Por outro lado com relação ao aspecto visual do alimento estes não poderiam estar visivelmente deteriorado quanto a sua textura é integridade.

Por outro referente à qualidade dos vegetais estas deveriam ser mantidas através da lavagem, higienização dos manipuladores e dos ambientes.

Quanto ao questionamento referente a alimento orgânico foi definido como aquele produzido de uma forma natural, sem aditivos e sem agrotóxicos.

Com referência a demanda pelos produtos orgânicos no Rio de Janeiro, poucas pessoas procuram este tipo de produto e pode se considerar por um lado por falta de disponibilidade e por outro lado quando disponível o preço mais alto.

Quando questionados com referência aos fatores que contribuiriam em termos de produção e conservação para melhoria dos produtos orgânicos foram mencionados as seguintes considerações: temperatura adequada do local de exposição; maiores estudos e desenvolvimento de novas tecnologias.

Pode-se observar com referência aos produtos orgânicos que o consumidor tem escassa informação. Pode ser consequência de um baixo consumo.

Finalmente podem se considerar dois aspectos importantes para melhorar o consumo de produtos orgânicos: maior informação, acessibilidade quanto a preço do produto. 
Quadro 3. Resultado dos participantes da sessão do Focus Group dos atributos dos produtos orgânicos

\begin{tabular}{|c|c|c|c|c|c|}
\hline $\begin{array}{l}\text { Alimentação } \\
\text { saudável }\end{array}$ & $\begin{array}{l}\text { Alimentos } \\
\text { que compõem } \\
\text { uma boa } \\
\text { alimentação }\end{array}$ & $\begin{array}{l}\text { Quais são } \\
\text { os vegetais } \\
\text { que você } \\
\text { mais } \\
\text { consome }\end{array}$ & $\begin{array}{l}\text { Onde costuma } \\
\text { comprar } \\
\text { vegetais }\end{array}$ & $\begin{array}{l}\text { Critério } \\
\text { usados na } \\
\text { compra dos } \\
\text { vegetais }\end{array}$ & $\begin{array}{l}\text { De que depende } \\
\text { a qualidade dos } \\
\text { vegetais }\end{array}$ \\
\hline $\begin{array}{l}\text { Pessoa deve } \\
\text { se sentir bem }\end{array}$ & Frutas & Alface & Mercado & Maturação & $\begin{array}{l}\text { Naõ pode ser } \\
\text { modificado } \\
\text { geneticamente }\end{array}$ \\
\hline $\begin{array}{l}\text { Traga benefício } \\
\text { nutricional }\end{array}$ & Verduras & Couve & Sacolão & Tamanho & Não ter agrotóxico \\
\hline $\begin{array}{l}\text { Destituída de } \\
\text { gordura animal }\end{array}$ & Legumes & Cenoura & Supermercado & $\begin{array}{l}\text { Limpeza do } \\
\text { local }\end{array}$ & $\begin{array}{l}\text { Segurança } \\
\text { Microbiológica }\end{array}$ \\
\hline Redunde em saúde & Peixe & Batata & Plantio & Preço & Higiene do local \\
\hline $\begin{array}{l}\text { Quando é } \\
\text { equilibrada }\end{array}$ & Carne magra & Tomate & Hortifruti & & Preço \\
\hline $\begin{array}{l}\text { Sem gordura } \\
\text { animal em excesso }\end{array}$ & $\begin{array}{l}\text { Nozes } \\
\text { oleaginosas }\end{array}$ & Berinjela & & & Rachaduras \\
\hline $\begin{array}{l}\text { Alimentos } \\
\text { variados sem } \\
\text { excesso }\end{array}$ & & Mamão & & & Partes podres \\
\hline $\begin{array}{l}\text { Com uso de carnes } \\
\text { magras }\end{array}$ & & Banana & & & Comercialização \\
\hline $\begin{array}{l}\text { Com alimentos } \\
\text { naturais }\end{array}$ & & Melancia & & & $\begin{array}{l}\text { Não deve estar } \\
\text { amassado }\end{array}$ \\
\hline $\begin{array}{l}\text { É muito chata } \\
\text { e sem sabor }\end{array}$ & & Maçã & & & \\
\hline $\begin{array}{l}\text { Quando não } \\
\text { se passa mal }\end{array}$ & & Melão & & & \\
\hline $\begin{array}{l}\text { Microbiologicamente } \\
\text { segura }\end{array}$ & & Abacate & & & \\
\hline
\end{tabular}


Quadro 4. Resultado dos participantes da sessão do Focus Group dos atributos dos produtos orgânicos

\begin{tabular}{|c|c|c|c|c|c|}
\hline $\begin{array}{l}\text { Como a } \\
\text { qualidade pode } \\
\text { ser mantida em } \\
\text { casa }\end{array}$ & $\begin{array}{l}\text { O que entende } \\
\text { por alimento } \\
\text { orgânico }\end{array}$ & $\begin{array}{l}\text { Demanda do } \\
\text { consumidor no } \\
\text { Rio de Janeiro }\end{array}$ & $\begin{array}{l}\text { Fatores que } \\
\text { contribuem } \\
\text { para melhoria } \\
\text { de produção e } \\
\text { conservação }\end{array}$ & $\begin{array}{l}\text { Qual a relação } \\
\text { entre a } \\
\text { informação e o } \\
\text { consumo orgânico }\end{array}$ & $\begin{array}{l}\text { O que } \\
\text { estimularia } \\
\text { você a } \\
\text { consumir } \\
\text { orgânicos }\end{array}$ \\
\hline $\begin{array}{l}\text { Através da } \\
\text { lavagem }\end{array}$ & $\begin{array}{l}\text { Produzido de } \\
\text { forma natural }\end{array}$ & $\begin{array}{l}\text { Poucas pessoas } \\
\text { procuram }\end{array}$ & $\begin{array}{l}\text { Temperatura } \\
\text { adequada do local } \\
\text { de exposição }\end{array}$ & $\begin{array}{l}\text { Pela escassez } \\
\text { de informação o } \\
\text { consumo é muito } \\
\text { baixo }\end{array}$ & $\begin{array}{l}\text { Maior } \\
\text { acesso }\end{array}$ \\
\hline Higienização & $\begin{array}{l}\text { Sem aditivos } \\
\text { e sem } \\
\text { agrotóxicos }\end{array}$ & $\begin{array}{l}\text { Pessoas que } \\
\text { tem mais } \\
\text { conhecimento } \\
\text { procuram }\end{array}$ & Maiores estudos & $\begin{array}{l}\text { Mercado poderia } \\
\text { informar }\end{array}$ & Preço \\
\hline $\begin{array}{l}\text { Preservação } \\
\text { em locais } \\
\text { apropriados }\end{array}$ & Sem tecnologia & $\begin{array}{l}\text { Pessoas com } \\
\text { mais cultura }\end{array}$ & $\begin{array}{l}\text { Desenvolver novas } \\
\text { tecnologias }\end{array}$ & $\begin{array}{l}\text { Profissionais da } \\
\text { área de saúde }\end{array}$ & $\begin{array}{l}\text { Maior } \\
\text { venda }\end{array}$ \\
\hline $\begin{array}{l}\text { Higiene das } \\
\text { mãos antes do } \\
\text { consumo }\end{array}$ & $\begin{array}{l}\text { Que preserve o } \\
\text { meio ambiente }\end{array}$ & $\begin{array}{l}\text { Pessoas } \\
\text { com maior } \\
\text { conhecimento } \\
\text { em alimentos }\end{array}$ & & $\begin{array}{l}\text { Equipes do } \\
\text { governo }\end{array}$ & \\
\hline $\begin{array}{l}\text { Comprar apenas } \\
\text { o necessário } \\
\text { para o consumo } \\
\text { diário }\end{array}$ & $\begin{array}{l}\text { Água e } \\
\text { solo não } \\
\text { contaminados }\end{array}$ & $\begin{array}{l}\text { Algumas } \\
\text { pessoas } \\
\text { rejeitam pelo } \\
\text { preço }\end{array}$ & & Mídia & \\
\hline Usar gelada & $\begin{array}{l}\text { Com } \\
\text { certificado }\end{array}$ & $\begin{array}{l}\text { Não consomem } \\
\text { por não } \\
\text { encontrarem } \\
\text { com facilidade }\end{array}$ & & $\begin{array}{l}\text { Palestras } \\
\text { educativas nas } \\
\text { escolas }\end{array}$ & \\
\hline \multirow[t]{3}{*}{ Usar ao natural } & $\begin{array}{l}\text { Ausência de } \\
\text { pesticidas }\end{array}$ & & & & \\
\hline & $\begin{array}{l}\text { Traz uma carga } \\
\text { Microbiana alta }\end{array}$ & & & & \\
\hline & $\begin{array}{l}\text { Sem } \\
\text { modificação } \\
\text { genética }\end{array}$ & & & & \\
\hline
\end{tabular}

\section{CONCLUSÕES}

Concluí-se que a utilização do Focus Group é eficiente, em casos onde se deseja conhecer qualitativamente os anseios do consumidor, com relação a determinado produto ou serviço, principalmente quando pouco se sabe sobre o tema a ser abordado.

O método pode ser utilizado para gerar outras hipóteses que poderão ser submetidas a futuras pesquisas usando métodos quantitativos, estimular novas idéias e conceitos, diagnosticar problemas potenciais de novos programas, gerar impressões sobre 
serviços, programas ou produtos, aprender como os participantes se expressam sobre determinado assunto, interpretar resultados quantitativos previamente obtidos e obter idéias de um grupo específico de consumidores. Além disso, a utilização do método de Focus Group tem como vantagem a rapidez e o custo; a interação direta com os participantes; a riqueza na obtenção dos dados, por ser aberto; a flexibilidade do método; a possibilidade da participação de crianças e não literatos e a facilidade de entendimento dos resultados. Nesse sentido podemos concluir pelos resultados encontrados que o consumo de produtos orgânicos é um mercado promissor quanto à sua exploração futura. Basta considerar que os orgânicos precisa de maior informação. Outro aspecto a ser considerado está relacionado com a qualidade do produto em si (textura, firmeza, aparência, cor e não geneticamente modificado).

\section{REFERÊNCIAS BIBLIOGRÁFICAS}

CALDER, B.J. Focus group and the nature of qualitative marketing research. Journal of Marketing Research, Chicago, v.14,p.353-364,1977.

DAVIES, A.; TITTERINGTON,A.J.; COCHRANE, C. Who buys organic food ? A profile of the purchases of organic food in Northern Ireland, British Food Journal, Bradford, v.97, n.10, p.17-23, 1995.

GREGOR, S.; GALASKA, S. S. The use of key information networks in assessment of community health. Family Med., n.22, p.11821, 1990.
KRUEGER, R.A. Focus group: a pratical guide for applied research. Newbury Park, Sage Publications, 1988.

MORGAN, D. L. Focus group as qualitative research. Newbury Park, Sage Publication, 1988. (Qualitative Research Methods Series 16).

PRODUTOS orgânicos: naturalmente rentáveis. Arco: Revista do Pequeno Produtor, Brasília, v.1, n.1, p. 8-10, nov.2001.

REGMI, A (Ed.). Changing structure of global food consumption and trade. Washington, DC, Market and Trade Economic Division, Economic Research Service. 2001. (USDA. Agriculture and Trade Report, WRS-01-1).

TROST, J. E. Statistically non-representative stratified sampling: a sampling techinique for qualitative studies. Qualit. Res., n.9, p.54-7, 1986.

UNCTAD. Organic food and beverages: world supply and major European markets. Geneva: ITC,1999.

WORD HEALTH ORGANIZATION. The focus group manual. Genebra, 1992. (Methods for Social Research in Tropical Disease, 1). 